\title{
A teoria de Kohlberg sobre o desenvolvimento do raciocínio moral e os instrumentos de avaliação de juízo e competência moral em uso no Brasil
}

\author{
Patricia Unger Raphael Bataglia \\ Alessandra de Morais \\ Universidade Estadual Paulista - Marília \\ Rita Melissa Lepre \\ Universidade Estadual de Paulista - Bauru
}

\begin{abstract}
Resumo
O presente artigo tem por objetivo abordar as bases, finalidades e composição de dois instrumentos de avaliação de juízo moral: a Moral Judgment Interview (MJ) e o Defining Issues Test (DIT), e um de competência moral: o Moral Judgment Test (MJT). Retoma a teoria do desenvolvimento moral de Kohlberg que fundamenta esses instrumentos, assim como os últimos estudos realizados com os mesmos. A MJI é uma entrevista semiestruturada que avalia o nível de juízo moral. O DIT é um teste objetivo que mede a proporção de respostas pós-convencionais. O MJT é um instrumento objetivo, que avalia a competência moral. Destaca-se a crescente utilização desses instrumentos em pesquisas sobre moralidade.
\end{abstract}

Palavras-chave: instrumentos de avaliação; juízo moral; competência moral

\begin{abstract}
Kohlberg's theory about moral judgment development and the instruments used for evaluation of moral judgment and moral competence in Brazil. This paper presents intends to address the objectives and composition of two instruments for evaluation of moral judgment: the "Moral Judgment Interview" (MJI) and the "Defining Issues Test" (DIT) and one for moral competence measurement: the "Moral Judgment Test" (MJT). It retakes Kohlberg's moral development theory which gives the foundation for these instruments. Presents Brazilian studies with each instrument. MJI is a semi-structured interview that evaluates the stage of moral judgment. DIT is an objective test that measures the percentage of post-conventional answers. MJT is an objective instrument that measures the moral judgment competence. Researches have used more and more these instruments.
\end{abstract}

Keywords: instruments for measurement; moral judgment; moral competence.

$\Lambda$ Psicologia da Moralidade é uma área que se tem fortalecido, no campo acadêmico. Por motivos de natureza social, política e científica, desde o final da década de 1970, verificamos um acentuado interesse pela moralidade e pela Educação Moral, e em valores. De acordo com Biaggio (1992, 2002), Pérez-Delgado, Serra Desfilis e Carbonel Vaya (1986), e Pérez-Delgado e Mestre Escrivá (1995), as pesquisas sobre moral foram ampliadas de forma extraordinária com os estudos de Lawrence Kohlberg (1927-1987). As pesquisas sobre o desenvolvimento moral, fundamentadas em Kohlberg, geraram a elaboração de alguns instrumentos de avaliação do juízo moral e da competência moral, que foram traduzidos e adaptados para a realidade brasileira, dentre os quais se destacam a entrevista semiestruturada de Kohlberg (MJI), o Defining Issue Test (DIT) e o Moral Judgment Test (MJT).

O presente artigo trata das bases, objetivos e composição desses instrumentos, levantando, também, alguns dos estudos recentes, realizados no Brasil, que os utilizam. Primeiro, é abordada a teoria sobre o desenvolvimento do raciocínio moral segundo Kohlberg; em seguida, são apresentados os instrumentos acima mencionados, tratando das últimas pesquisas e dos desafios que se colocam para o futuro. Cabe esclarecer o motivo da escolha desses instrumentos e não outros. De acordo com levantamento realizado nas bases BVS (Biblioteca Virtual em Saúde) e Scielo (Scientific Eletronic Library Online) com os descritores 'moral' e 'Kohlberg', encontrou-se cinco instrumentos de avaliação do juízo moral e da competência moral em uso no Brasil: além dos mencionados anteriormente, que serão objeto de estudo desse artigo (MJI, DIT e MJT), há estudos utilizando o "Socio-moral Reflection Objective Measure" (SROM), de Gibbs, Arnold e Burkhart (1984) e o "Problem Identification Test" (PIT), instrumento construído por Hebert, Meslin, Dunn, Buirn e Reid (1990). Optou-se em não abordar esses dois últimos instrumentos no presente artigo, em 
função de seu uso ser muito restrito no Brasil quando comparado ao DIT e a MJI. O MJT será tratado em função de ser o único instrumento que mensura a competência moral.

\section{O desenvolvimento do raciocínio moral na perspec- tiva de Lawrence Kohlberg}

As pesquisas de Kohlberg (1992) incluem-se no grupo das teorias cognitivo-evolutivas, assim como as de Piaget, tendo como base o pressuposto de que o desenvolvimento pressupõe transformações básicas das estruturas cognitivas, enquanto totalidades organizadas em um sistema de relações, as quais conduzem a formas superiores de equilíbrio, resultantes de processos de interação entre o organismo e o meio. Kohlberg (1992) afirma que a teoria dos estágios é um dos pontos centrais da postura cognitivo-evolutiva e, da mesma forma que o desenvolvimento cognitivo, o moral também ocorre por meio da evolução de estágios. Os estágios de raciocínio moral, propostos por Kohlberg, são de raciocínio de justiça e não de emoções ou ações. Kohlberg (1992) destaca que sua definição de moralidade e desenvolvimento moral deriva das definições de Hare (1982), para quem o centro da moralidade é a justiça ou os princípios de justiça. "Essa centralidade da justiça deriva também do trabalho de Piaget (1932/1994) sobre o desenvolvimento do julgamento moral, no qual ele definiu a moralidade como uma atitude de respeito pelas pessoas e pelas regras, aliando-se, portanto, a Kant" (Biaggio, 2002, p. 37).

Entretanto, Kohlberg (1992) chegou à conclusão de que os conceitos de heteronomia e autonomia, propostos por Piaget (1932/1994), não eram suficientes para classificar os tipos de raciocínio moral que ele encontrou, em seus estudos com adolescentes e adultos. Com base nisso, propõe a existência de seis estágios de raciocínio moral, os quais podem ser agrupados em três níveis: o pré-convencional, o convencional e o pósconvencional. O nível pré-convencional contém os estágios 01 e 02. Nesse nível, o indivíduo julga o certo e o errado, apoiado apenas em seus interesses próprios, o que inclui o medo da punição. As questões morais são colocadas considerando-se somente o interesse das pessoas implicadas. No estágio 01 , o indivíduo obedece às normas sociais por medo do castigo que pode vir a receber, sendo denominado por Kohlberg (1992) de estágio da moralidade heterônoma. No estágio 02 , o indivíduo apresenta um raciocínio moral egocêntrico e segue as normas pensando em interesses próprios, esse é considerado o estágio do individualismo. No nível convencional, que contempla os estágios 03 e 04, a ação moral correta é aquela baseada nas convenções e regras sociais determinadas por pessoas que se apresentem como autoridades ou instituições reconhecidas socialmente. $\mathrm{O}$ indivíduo formula juízos morais tendo como referência as regras do grupo social e as expectativas que este tem sobre ele. O estágio 03 , também denominado de orientação do tipo "bom menino" (Menin, 1996), caracteriza-se pela necessidade de cumprir com aquilo que as pessoas esperam, como ser um bom filho, um bom amigo ou um bom marido. Há uma consciência inicial de que os interesses coletivos são mais importantes do que os individuais. $\mathrm{O}$ estágio 04 tem como perspectiva moral a manutenção da ordem social e daquilo que foi proposto pelas autoridades sendo que, para tanto, todos devem colaborar com a organização social e com as instituições. Finalmente, há o nível pós-convencional, que compreende os estágios 05 e 06 . Nesse nível, o correto é agir guiado por princípios morais universais, pautados pela reciprocidade e pela igualdade. O pensamento é regido por princípios morais e éticos e não por regras sociais, que só serão aceitas se estiverem fundamentadas em princípios e valores gerais. No estágio 05 , o raciocínio moral considera o contrato social e os direitos individuais, com orientação moral do tipo "contratual-legalista" (Menin, 1996). Já o estágio 06 é caracterizado pelos princípios éticos universais e considerado o mais evoluído por Kohlberg. Segundo Biaggio (2002), a última formulação que Kohlberg propôs em sua teoria considera a avaliação da entrevista de julgamento moral como uma atividade interpretativa (hermenêutica). Esse aspecto é contemplado em Colby e Kohlberg (1987) e relaciona-se, sobretudo, às ideias do filósofo alemão Habermas (1983), da Universidade de Frankfurt, com quem Kohlberg interagiu bastante, nos últimos anos de sua vida.

Kohlberg (1992), pensando numa melhor definição de estágio moral, propôs a existência de subestágios, denominados A e B. Dessa forma, dentro de um mesmo estágio, podemos distinguir duas formas de raciocínio: uma com orientação heterônoma, baseada em regras e na autoridade, representada pelo subestágio A; e outra com orientação autônoma, baseada em princípios, justiça, igualdade e reciprocidade, representada pelo subestágio B. Para Kohlberg, sujeitos que apresentam um raciocínio moral do subestágio $B$ são, provavelmente, mais comprometidos com a ação moral daquilo que consideram justo do que os sujeitos do subestágio A.

Ao propor os subestágios A e B, Kohlberg (1992) define estilos de juízo moral para cada estágio: um estilo heterônomo e um estilo autônomo. Esses estilos estabelecem uma estreita relação com a conduta moral, isto é, um indivíduo do estágio 3, do nível convencional, com estilo autônomo, apresentará maior probabilidade de ter uma conduta moral vinculada à sua concepção, do que um indivíduo do estágio 4, do nível convencional, com estilo heterônomo.

As teorias de Piaget e Kohlberg receberam, ao longo dos anos, críticas relacionadas à sua formulação, sobretudo no âmbito da Psicologia. Entre elas, podemos citar as de Gilligan (1993), Campbell e Christopher (1996) e Flanagan (1996), entre outros. Tais críticas, entre outros pontos, consideram que essas teorias têm uma preocupação apenas com a moralidade masculina baseada na justiça, assim como desvalorizam a dimensão afetiva e as emoções. No entanto, para LaTaille (1998), as teorias de Piaget e Kohlberg continuam sendo as mais fortes referências para os estudos sobre a moralidade humana, no âmbito da Psicologia, apesar das turbulências que atingiram tanto a definição do objeto a ser estudado quanto as variáveis psicológicas escolhidas para explicar o desenvolvimento moral.

\section{A Moral Judgment Interview (MJI): a entrevista semiestruturada de Kohlberg}

A Moral Judgment Interview (MJ) é uma entrevista semiestruturada que tem como objetivo a avaliação do juízo moral. Caracteriza-se por uma "conversa" sobre três dilemas morais, sendo composta por três versões paralelas: A, B e C. 
Em cada dilema hipotético, aparecem sempre valores morais em conflito. Na forma "A", os valores em conflito, ao longo dos três dilemas, são: vida/lei; moralidade/consciência/castigo e contrato/ autoridade. $\mathrm{Na}$ forma "B": vida(qualidade)/lei/conservação da vida; moralidade/consciência/castigo e contrato/autoridade. E na forma "C": vida (qualidade)/vida (quantidade); moralidade/ consciência/castigo e contrato/lei (Díaz-Aguado \& Medrano, 1999).

A proposição do estágio predominante de raciocínio moral é feita por meio da análise das respostas às perguntas que se seguem aos dilemas morais. A MJI deve ser oral e, se possível, gravada, para ser transcrita posteriormente. A duração de sua aplicação pode variar definindo-se uma média de 60 minutos para os três dilemas. A avaliação da MJI é bastante complexa. Inicialmente, Kohlberg buscou desenvolver uma entrevista baseada no método clínico piagetiano, nos moldes das realizadas por Piaget (1932/1994) no "Juízo Moral na Criança”, sem a intenção de padronizá-la. Contudo, devido às pressões do mundo acadêmico norte-americano da época (décadas de 70 e 80), Kohlberg e seus colaboradores julgaram necessário pensar em um manual de avaliação da entrevista que pudesse oferecer medidas objetivas sobre o julgamento moral (Biaggio, 2002). Diversas foram as tentativas até a elaboração final do Standarized Scoring Manual (Colby \& Kohlberg, 1987), que atingiu um grau maior de confiabilidade e objetividade nas pontuações das entrevistas, embora ainda dependente de avaliação qualitativa (Biaggio, 2002).

Vale ressaltar aqui que Colby e Kohlberg (1987) realizam um estudo extenso sobre a questão da validade da Entrevista de Juízo Moral, detendo-se na validade de constructo e não na validade preditiva ou com relação a critérios externos. Os critérios utilizados para avaliar a validade foram os dois mais centrais pressupostos teóricos da sequência de estágios: invariância de sequência e totalidade estrutural. O primeiro desses critérios é confirmado em estudos longitudinais e o segundo na avaliação por juízes. Nos estudos brasileiros, não há relatos de estudos longitudinais. No entanto, no que diz respeito à totalidade estrutural, encontram-se confirmações alcançadas nos estudos de Bataglia (1996), Biaggio (1984) e Lepre (2005).

A MJI permite identificar a problemática, a norma e o elemento utilizados nas respostas do entrevistado, possibilitando a construção de um perfil moral. A problemática é o tema moral suscitado pelo dilema. Cada dilema foi elaborado visando a levantar problemáticas opostas (polaridades temáticas), as quais levam o entrevistado a justificar seu argumento baseado em uma ou outra. A norma é o conjunto completo de valores usado pelo entrevistado. Representa a justificativa que ele oferece para a sua escolha pró ou contra a atitude do personagem do dilema. As normas possíveis de serem empregadas, segundo a teoria de Kohlberg (1992) e com base em dados empiricamente acumulados por ele, são as seguintes: Vida (preservação e qualidade/quantidade), Propriedade, Verdade, Afiliação, Amor Erótico e Sexo, Autoridade, Lei, Contrato, Direitos Civis, Religião, Consciência e Punição. (Díaz-Aguado \& Medrano, 1999). O elemento, por sua vez, é a unidade menor a ser analisada e representa a forma pela qual o entrevistado aplicou a norma ao caso específico do dilema. No Standarized Scoring Manual
(Colby \& Kohlberg, 1987), os elementos podem ser modais ou de valores. De acordo com Bataglia (1996), os elementos modais correspondem à razão deontológica, e tratam basicamente de direitos e deveres. Os elementos de valor dizem respeito à ética teleológica, que leva em consideração as consequências das ações morais.

Os estágios atribuídos aos sujeitos analisados podem ser, segundo Colby e Kohlberg (1987), estágios puros, transicionais (quando há prevalência de um estágio mais baixo, porém há a presença de raciocínio de um estágio posterior) e em consolidação (quando há prevalência de um estágio mais alto, porém há a presença de raciocínio de um estágio anterior). Apenas sujeitos que possuam mais de $80 \%$ de seu pensamento em um único estágio são considerados puros. A maioria das pessoas é transicional ou em consolidação (Díaz-Aguado \& Medrano, 1999).

No Brasil, a Moral Judgment Interview (MJ) tem sido empregada por pesquisadores como Bataglia (1996), Biaggio (1984), Koller, Biaggio e Viñas (1992), Lepre (2005), Lepre e Martins (2009), Lins (1993), entre outros. No entanto, há críticas em relação a esse instrumento que devem ser consideradas. Conforme Rest, Narvaez, Bebeau e Thoma (1999) uma das críticas direcionadas à MJI é que ela apresenta limitações no que diz respeito à capacidade de seus dilemas em abranger adequadamente todos os domínios morais, tendo como foco aspectos da macromoralidade, sobretudo aqueles relacionados à justiça, negligenciando-se os relacionamentos pessoais mais íntimos e o papel da religião na formação do pensamento moral. Da mesma forma, Campbell e Christopher (1996) indicam que tanto os estágios como os instrumentos utilizados por Kohlberg são limitados por se reportarem somente a assuntos de direitos e de justiça legal, não alcançando temas que abarquem a moralidade privada e o self. Mais uma restrição apontada por Campbell e Christopher (1996) em relação ao método de Kohlberg é a de que existem posições de raciocínio na filosofia moral que não se enquadram em nenhum dos estágios de desenvolvimento do raciocínio moral prescritos pelo teórico. Como contra-exemplo a essa abordagem, os autores nos apresentam o Eudemonismo aristotélico propondo, com base nessa corrente filosófica, que haja no interior do domínio moral uma reintegração entre o desenvolvimento moral, de valores e da personalidade.

Além disso, de acordo com Rest et al. (1999) teóricos indicam as limitações da explanação verbal como um método válido para a atribuição da estrutura cognitiva de alguém. Shweder et al (1987, citado por Rest et al., 1999) afirmam que muitas vezes a metodologia de Kohlberg verifica mais a habilidade verbal do sujeito do que seu real conhecimento ou desenvolvimento moral.

Díaz-Aguado e Medrano (1999) destacam que pelo fato ter se dirigido muito mais à estrutura de raciocínio, do que ao conteúdo, em sua entrevista ele generaliza a explicação e o desenvolvimento das estruturas morais, sem levar em conta os conflitos reais e as situações específicas das quais se tomam as decisões morais. Lourenço (2002) aponta que essa distinção entre estrutura e conteúdo não é completa na avaliação da entrevista, e enfoca a complexidade da MIJ tanto no que concerne à sua condução como à forma de codificação. 
Tendo em vista, especialmente, esse último aspecto, outros instrumentos foram desenvolvidos e estão sendo usados por pesquisadores brasileiros. Os que serão tratados na sequência (DIT e MJT) vêm sendo empregados por pesquisadores brasileiros que se dedicam ao estudo da moralidade, e têm possibilitado a avaliação do julgamento e/ou da competência moral em diferentes contextos - escolas, universidades, ambiente de trabalho, sistemas prisionais ou sócio-educativos, etc. - e relacionados a uma diversidade de fatores, tais como: formação acadêmica e profissional, características da personalidade, gênero, orientação social, tomada de perspectiva e capacidade empática, maturidade e autoconceito, delinquência, programas de Educação Moral e em Valores, religiosidade, uso de álcool, dentre outros (Bataglia, 2001; Camino et al., 1994; Camino, Moraes, \& Galvão, 2006; Koller et al., 1994; Mattos, Shimizu, \& Bervique, 2008; Sambuy, Barros, Nogueira, Marcolino, \& Mathias, 2005; Shimizu, 2002, 2004).

\section{$O$ Defining Issues Test (DIT) e a abordagem neo- kohlberguiana baseada no DIT}

A primeira versão do Defining Issues Test (DIT) - a qual denominamos de DIT-1 - foi elaborada por Rest, em 1979 (Rest, 1986). Esse instrumento foi traduzido, inicialmente, por Bzuneck, em 1979, que o denominou, em língua portuguesa, "Teste de Julgamento de Situações"; reformulado, de acordo com o contexto brasileiro, por Camino, Luna, Alves, Silva e Rique (1988, 1989), passando a ser chamado de "Opiniões sobre Problemas Sociais".

O teste é constituído por seis dilemas morais - versão longa - ou três dilemas - versão curta; para cada um deles, o sujeito deve avaliar doze alternativas de respostas, havendo uma escala de cinco graus de importância para a resolução. $\mathrm{O}$ avaliado deve selecionar hierarquicamente as quatro alternativas que considera mais importantes para a solução do dilema. Dessa forma, é possível obter-se um escore, denominado índice $\mathrm{P}$, que representa a percentagem de nível pós-convencional (estágios 5A, 5B e 6). $O$ teste permite, ainda, visualizar os padrões de respostas que os sujeitos oferecem em cada estágio (2, 3, 4, 5A, 5B e 6), assim como as respostas A, "antiestablishment", que refletem o conceito de estágio 4 e meio, mas são, na verdade, indicadoras de uma aparente regressão a respostas mais primitivas, tipo estágio 2, por ocasião da passagem do estágio 4 para o estágio 5, ou seja, do nível convencional para o pós-convencional.

Enquanto Kohlberg sempre fez da técnica de entrevista seu único instrumento de coleta de dados, Rest et al. (1999) apresentam o DIT como uma nova proposta de investigação, salientando as seguintes vantagens em relação à entrevista: não requer grande habilidade verbal dos sujeitos, oferece maior controle da situação de teste, e, ainda, possibilita uma correção objetiva e computadorizada. Embora reconheçam o mérito da teoria de Kohlberg e ainda capturem a essência de suas principais ideias, Rest et al. (1999) erigem, com base em 25 anos de pesquisa com o DIT, uma abordagem que denominam neokohlberguiana, a qual apresenta algumas diferenças elementares em relação ao trabalho de Kohlberg.

Em vez de descreverem o desenvolvimento moral em estágios com diferentes operações de justiça, como Kohlberg o faz, Rest et al. (1999) apresentam uma definição de esquemas de desenvolvimento - esquema de interesse pessoal, de manutenção das normas e pós-convencional - que é também uma reconstrução do raciocínio de justiça, o qual, sem referenciar as operações, focaliza a problemática humana de como organizar a cooperação na sociedade. É com base nesses três esquemas que os 12 itens após cada história do DIT são agrupados para, posteriormente, serem pontuados.

Correspondendo aos estágios 1, 2 e 3 de Kohlberg, o esquema de interesse pessoal é caracterizado pela necessidade de proteção e bem-estar de si mesmo e de pessoas com quem se tem um relacionamento familiar ou afetivo. $\mathrm{O}$ esquema de manutenção das normas, derivado do estágio 4 de Kohlberg, é descrito por meio dos seguintes elementos: necessidade de normas para o estabelecimento de um sistema amplo de cooperação; utilização da lei formal para a estabilização de expectativas e envolvimento entre as pessoas que não são familiares, íntimas ou não se conhecem; uniformidade na aplicação das leis; reciprocidade parcial, uma vez que as leis estabelecem a reciprocidade entre os participantes da sociedade, no entanto, parcial, porque, algumas vezes, a obediência à lei pode não favorecer todas as pessoas de forma equitativa; e dever orientado, pois o respeito pelo sistema social é representado pelo dever de respeito à autoridade, que é legitimado pelas estruturas hierárquicas da sociedade. Apesar de enfatizarem os aspectos positivos do esquema de manutenção das normas e salientarem sua inerência ao desenvolvimento, Rest et al. (1999) advertem que esse esquema, quando exagerado, pode ser prejudicial, abreviando os direitos básicos humanos e a liberdade civil. No esquema pós-convencional, por sua vez, são propostos quatro elementos: a primazia do critério moral, em que a pessoa percebe que as leis, regras, códigos e contratos são arranjos que prescrevem comportamentos e que podem ser organizados de diferentes formas; a busca de um ideal construtivo para transformar a sociedade; a capacidade de compartilhar ideais, em justificar um ato que sirva aos objetivos do grupo, gere novas cooperações e bem comum, e seja consistente e pautado em princípios; e a reciprocidade total, que implica não somente a aplicação uniforme das normas sociais, mas também em seu questionamento.

Rest et al. (1999) não consideram o desenvolvimento moral como uma mudança abrupta de um degrau para outro, ocasionada pelo tempo - como Kohlberg o faz, mediante a noção de estágios piagetianos duros -, mas sim como um movimento ascendente, em termos de mudanças graduais no uso e preferência por pensamentos morais mais desenvolvidos, e o uso restrito de um estágio em detrimento do uso mais acentuado de outro (estágios mais altos sendo mais utilizados e estágios mais baixos diminuindo em seu uso). A avaliação do desenvolvimento não consiste no enquadramento do indivíduo em determinados estágios; na verdade, repousa na análise do grau com que o sujeito usa vários tipos de pensamentos.

Segundo Rest et al. (1999) existem inúmeros estudos com o DIT, os quais, além de bastante atuais, são numerosos e estão publicados. Conforme esses autores, desde a década de 70 , as pesquisas com o DIT têm-se acumulado em uma velocidade constante, perfazendo um total de mais de 400 publicações, até o momento. Além disso, vários pesquisadores, em nome do 
Center for the Study of Ethical Development, têm-se empenhado, recentemente, em um novo ciclo de estudos para a produção de uma versão mais atualizada do DIT, elaborada em 1998 por Rest e Narvaez, denominada DIT-2, cuja tradução e adaptação ao contexto brasileiro foram realizadas por Biaggio, Shimizu e Martinez (2001).

Em estudos desenvolvidos até o momento, comparandose o DIT-1 com o DIT-2, tem-se demonstrado que este é mais moderno, mais curto - sendo composto por cinco dilemas morais -, possui instruções mais claras e dinâmicas, invalida um número menor de sujeitos pelo teste de não-confiabilidade e parece produzir uma tendência sutilmente mais forte de validade e confiabilidade. Ainda que esses aspectos positivos já tenham sido vislumbrados em alguns estudos com o DIT-2, Rest e Narvaez (1998) advertem, no entanto, sobre a necessidade da realização de mais pesquisas a respeito, pois existem centenas de estudos com o DIT-1, com dados colhidos em mais de 45.000 indivíduos, enquanto o número de pesquisas com o DIT-2 é muito limitado.

Rest et al. (1999) explicitam, igualmente, os critérios de validade sobre os quais a pesquisa com o DIT (tratam especialmente do DIT-1, porque existe um número significativamente maior de pesquisas com o seu uso) se sustenta: diferenciação de grupos em relação a medidas mais altas ou mais baixas de juízo moral, indicando especialmente uma diferenciação mais forte em relação à variável "nível educacional"; demonstração de significante mudança ascendente em estudos longitudinais; sensibilidade a intervenções direcionadas à promoção de raciocínios morais, por meio de sua utilização em pré e pósteste para se medir a efetividade dos programas de Educação Moral; evidência de desenvolvimento hierárquico, isto é, de que escores mais altos indicam um desenvolvimento moral mais avançado e melhor do que escores mais baixos (por intermédio de estudos que correlacionam positivamente os escores do DIT com medidas de compreensão moral, desenvolvimento de ego, operações formais, juízo reflexivo); previsibilidade significativa do comportamento da vida real, demonstrada pela correlação do DIT com medidas de comportamento pró-social ou antissocial e com atitudes e escolhas políticas; e adequada confiabilidade, comprovada por consistência interna apropriada, diversas verificações de confiabilidade para a detecção e invalidação do teste e resultados em "teste-reteste" e no Guttman. Rest et al. (1999) reconhecem, contudo, que tanto o DIT-1 como o DIT-2 possuem alguns problemas: em especial, os participantes podem preenchê-los aleatoriamente, fornecendo dados falsos, e respondê-los de forma diferente daquela planejada por seus criadores; seus itens podem parecer ambíguos para alguns participantes ou ocasionar reações peculiares e, ao contrário da entrevista, que subestima o desenvolvimento da pessoa (escassez de estágios 5 e 6), o DIT pode superestimá-lo.

Shimizu $(2002,2004)$ avaliou a fidedignidade da tradução e adaptação brasileira do Definig Issues Test-2. Seu estudo questiona se o DIT-1 e o DIT-2 são adequados à realidade brasileira, uma vez que os índices de fidedignidade obtidos nas amostras americanas por Rest et al. (1999) demonstraram ser significativamente superiores aos alcançados pelas brasileiras. O coeficiente alfa de Cronbach (a) foi calculado, neste estudo, tendo-se por base a pontuação bruta do índice $\mathrm{P}($ estágios $5 \mathrm{~A}$,
5B e 6) que os testandos obtiveram em cada história. Verificouse o grau de variação dessa pontuação em cada sujeito e entre todos os sujeitos. Observou-se a proximidade entre o valor do coeficiente alfa do DIT-2 $(\alpha=0,339)$ e do DIT-1 $(\alpha=0,385)$. Quando comparados os resultados do alfa das versões brasileiras do DIT-1 e DIT-2 com os das versões originais americanas, os primeiros (tanto a versão do DIT-1, já utilizada há mais de uma década no Brasil, como a do DIT-2, que acaba de ser concluída) revelam-se bem menores que aqueles obtidos por Rest e colaboradores (1999) em relação ao DIT-1 $(\alpha=0,78)$ e ao DIT-2 $(\alpha=0,70)$.

Apesar desses resultados, os testes revelaram ser sensíveis ao controle das variáveis selecionadas na pesquisa (status socioeconômico, nível educacional e região de procedência), apontando para tendências distintas, no interior da amostra investigada. Verificou-se, inclusive, que essas tendências coincidem com os estudos de Koller et al. (1994) e de Rest et al. (1999), as quais evidenciam a existência de uma diferenciação de grupos em relação a medidas mais altas ou mais baixas de juízo moral - principalmente, segundo pesquisas desses últimos autores, em relação à variável nível educacional. Todavia, os dados avaliados por Shimizu $(2002,2004)$ indicaram que a versão brasileira do DIT-2, elaborada em 2001, ainda não está satisfatoriamente adequada.

Shimizu $(2002,2004)$ e Shimizu e Urano (2004) expõem, também, algumas ponderações sobre a utilização do DIT-1 e do DIT-2, em pesquisas sobre moralidade. Os dados expostos em seus estudos demonstram que o DIT-1 e o DIT-2 podem revelar e confirmar diferentes formas de moralidade e de juízos morais, mas, igualmente, podem, especialmente quando usados como únicos instrumentos de investigação, conduzir a conclusões equivocadas e estereotipadas. Dessa maneira, conclui-se que a utilização desses instrumentos de medida - objetivos e fechados - deve ser acompanhada de muita cautela e, preferencialmente, de outros recursos investigativos.

\section{O Teste de Juizo Moral elaborado por Georg Lind- MJT (Moral Judgment Test)}

Em 1977, Georg Lind elaborou o Moral Judgment Test (MJT), com o objetivo de avaliar a competência do juízo moral. Esse constructo foi formulado por Lawrence Kohlberg, em 1964 (citado por Lind, 1999, p. 1), como a "capacidade de tomar decisões e emitir juízos morais (baseados em princípios internos) e agir de acordo com tais juízos". Kohlberg direcionou suas pesquisas para a investigação do juízo moral e estágios de desenvolvimento moral, enquanto Lind prosseguiu as investigações a respeito da competência.

O MJT trata de um aspecto do desenvolvimento moral que não é contemplado pelos demais instrumentos de avaliação moral existentes, ou seja, avalia a capacidade do sujeito em aplicar a estrutura de juízo em situações adversas. Assim como o MJI e o DIT, esse instrumento trabalha com dilemas morais. No entanto, solicita-se que sejam avaliados argumentos com diversas orientações morais, refletindo opiniões a favor e contra a decisão do personagem, isto é, o individuo deve apreciar argumentos a favor e contra sua própria opinião.

Quando apresentamos um dilema ao sujeito e ele argumenta 
ou reconhece argumentos a favor de sua própria opinião, evidencia-se a atitude moral que implica suas crenças, valores e conceitos. No lugar de medir simplesmente a atitude moral do sujeito, o MJT propõe uma tarefa moral difícil, que é o reconhecimento da qualidade de argumentos contrários à opinião do sujeito. Isso pressupõe outra capacidade que naturalmente envolve a estrutura cognitiva, porém, mais do que isso, exige uma postura não dogmática em relação a sua própria atitude. É essa capacidade (competência) que o MJT se propõe mensurar. Muitas tarefas morais podem ser imaginadas para avaliarmos a competência moral, mas poucas são factíveis e/ou válidas. A tarefa proposta pelo MJT é a avaliação de contra-argumentos. Isso corresponderia a colocar o sujeito frente a uma situação em que não é possível seguir o curso do que seria sua decisão, seus valores, e exigir que fundamente outro curso de ação.

O MJT se baseia na teoria do duplo aspecto do desenvolvimento moral, ou seja, há aspectos cognitivos e afetivos envolvidos na competência moral. A teoria do duplo aspecto do desenvolvimento moral tem suporte nas idéias de Piaget a respeito do paralelismo afetivo-cognitivo. É bem conhecido que Piaget considerava afeto e cognição como aspectos indissociáveis e complementares de uma mesma conduta (Piaget, 1997) e a comparação que faz entre a afetividade como aspecto energético, e a inteligência como o aspecto estrutural do comportamento humano (Piaget, 1954).

A avaliação do estágio de juízo moral, concebida por Kohlberg no MJI, trouxe uma inovação para a Psicologia Moral, que foi a proposta de avaliar não apenas a atitude moral, mas a habilidade dos sujeitos em aplicar valores ou princípios em situações complexas para resolver conflitos. Entretanto, as questões levantadas por Lind, as quais originaram a elaboração do MJT, permaneceram em aberto: quando o sujeito responde às questões de um dilema, está de fato refletindo o seu nível de juízo moral ou o seu compromisso com a defesa de um ideal? $\mathrm{Na}$ avaliação realizada pelo $\mathrm{MJI}$, consideram-se os aspectos cognitivos e afetivos integrados, mas distintos, ou ocorre uma confusão entre as duas dimensões? A teoria do duplo aspecto do desenvolvimento moral enfatiza que para uma descrição compreensiva do comportamento moral, ambas, propriedades afetivas e cognitivas devem ser consideradas. (Lind, 1999). A avaliação do MJT leva em conta a indissociabilidade de afeto e cognição, mas a possibilidade de distingui-los. As duas dimensões do comportamento moral - afetivo e cognitivo - não se apresentam necessariamente conectadas, embora ocorram de modo integrado, isto é, apesar de muitos indivíduos preferirem argumentos de estágios morais superiores, apenas aqueles com estruturas mentais reversíveis podem ser, também, competentes moralmente, ou seja, apresentar uma preferência pelos mesmos estágios quando avaliam contra-argumentos, ou argumentos rivais à sua opinião. É importante lembrar que a reversibilidade cognitiva por si só, igualmente, não garante a competência moral, o que a reduziria a uma operação intelectual.

Comparando o MJT com o DIT, podemos compreender melhor a diferença entre as propostas de mensuração dos aspectos afetivo e cognitivo de ambos os instrumentos. O DIT mensura quão consistentemente (aspecto cognitivo) o sujeito prefere (aspecto afetivo) argumentos pós-convencionais.
Note-se que ambos os aspectos são tratados, porém, de modo integrado ou até misturados. Não sabemos se a consistência se deve ao desenvolvimento moral ou simplesmente ao desejo de defender determinado ponto de vista. Quando o MJT mensura a consistência das respostas do sujeito, esta independe da sua preferência, ou seja, a avaliação é da capacidade de lidar com a tarefa de diferenciar a qualidade dos argumentos, independentemente da preferência por um curso de ação ou outro.

O MJT foi originariamente elaborado com dois dilemas: um sobre roubo e outro a respeito da eutanásia. O sujeito é convidado a avaliar a decisão do personagem, em uma escala de Likert de -3 a +3 . Em seguida, é confrontado a 12 argumentos, sendo seis a favor da decisão do personagem e seis contra. Tais argumentos são elaborados conforme os diferentes estágios de desenvolvimento moral. Os escores mais altos são concedidos a sujeitos que demonstram capacidade para apreciar a qualidade moral de um dado argumento, independentemente do fato de estarem de acordo, ou não, com o conteúdo da argumentação.

$\mathrm{O}$ MJT, mais do que um teste, é um experimento. Ou seja, há uma situação estruturada, variáveis controladas e uma estrutura pré-determinada, as quais permitem a avaliação da resposta sem ambiguidades (Lind, 1999, p. 7-8). O objetivo central desse experimento é descrever o tipo de avaliação que o sujeito faz acerca de situações e argumentos (Lind, 1999, p. 8). As variáveis independentes são os dilemas e os argumentos a favor e contra a decisão do personagem do dilema, colocados em seis diferentes níveis de juízo moral. A variável dependente é representada pelo comportamento de ajuizar do sujeito. É importante destacar que a avaliação dos argumentos a favor da própria decisão mostra qual o nível de discurso moral preferido pelo sujeito, enquanto os argumentos contrários à própria decisão indicam o quanto o sujeito se deixa determinar pelos próprios ideais ou pela qualidade dos próprios argumentos. $\mathrm{O}$ processo de desenvolvimento e validação do MJT para novas línguas exige tradução, retrotradução, trabalho empírico e testes que demonstrem que a nova versão ou o novo dilema desenvolvido mantém: preferência por estágios crescentes em relação ao escore de competência, correlação maior entre estágios vizinhos e paralelismo afetivo-cognitivo.

As traduções e adaptações feitas no México (Moreno, 2005) e no Brasil (Bataglia, 2001) evidenciaram um viés cultural, ou seja, os sujeitos obtiveram escores de competência moral equivalentes aos dos sujeitos de outros países, quando respondiam ao dilema do roubo, mas um escore muito baixo, quando respondiam ao dilema da eutanásia. Esse fenômeno, denominado segmentação moral, levou à necessidade do desenvolvimento de outro dilema, que também tratasse do valor da vida humana, mas que não envolvesse um valor religioso. $\mathrm{O}$ dilema do juiz (que aborda a questão da quantidade de vidas versus o respeito a uma vida) passou a integrar o MJT chamado então MJT-xt (estendido).

O MJT tem uma utilidade específica para as pesquisas de desenvolvimento moral, que é avaliar métodos educacionais em relação ao seu poder de elevar a competência moral dos sujeitos submetidos a eles. Bataglia (2001) descreve o uso do MJT como forma de avaliação de um processo de intervenção realizado no curso de Psicologia. Schillinger (2006) avalia o primeiro 
e último anos de três cursos de graduação, em três países, buscando verificar se o ambiente acadêmico tem influência na construção da competência moral. Oliveira (2008) observa o papel da formação universitária na construção da competência moral do enfermeiro, estudando uma escola interacionista, com proposta de métodos ativos. As pesquisas fora do Brasil também utilizam o MJT para avaliação de processos educacionais, a exemplo de Glanzer, Nipe e Lind (2007) que investigaram a influência da experiência de intercâmbio cultural em outros países na construção da competência moral; de Moreno (2005), que apresenta os resultados de seus estudos sobre a construção da competência moral após intervenções no ensino superior; de Slovácková (2001), examinando a competência moral em estudantes de medicina, dentre outros.

\section{Considerações finais}

O objetivo deste artigo foi apresentar as bases, objetivos e composição de dois instrumentos de avaliação do juízo moral (MJI e DIT) e um da competência moral (MJT) que têm sido utilizados em pesquisas brasileiras. Fica claro que a opção por um desses instrumentos depende do interesse específico do pesquisador.

A Moral Judgment Interview (MJI) é o resultado de décadas de trabalho e empenho em direção ao desenvolvimento de um método empírico de avaliação do juízo moral. Avalia qualitativamente o estágio de desenvolvimento moral, é aplicada individualmente e, por ter o formato de uma entrevista semiestruturada, leva um tempo maior para aplicação. Naturalmente, os dados são bastante ricos, contudo, a entrevista não permite trabalho com amostras extensas. Essa metodologia foi amplamente divulgada e, com base na MJI, outros instrumentos de medida moral foram elaborados, servindo de ferramenta para muitos pesquisadores, de diversas áreas - Educação, Psicologia, Sociologia, Filosofia, dentre outras - interessados no desenvolvimento moral. Verifica-se, entretanto, com fundamento em extensa revisão bibliográfica, que os instrumentos objetivos, como o DIT e o MJT, têm sido mais empregados, devido à maior facilidade de apuração dos resultados, em relação à MJI, a qual, apesar de possuir um manual detalhado de instruções, está muito mais vulnerável a interferências subjetivas, por parte do pesquisador, por ser uma entrevista composta de questões abertas.

O DIT calcula a proporção de respostas pós-convencionais de modo objetivo, fator que possibilita trabalhar com grandes amostras. No entanto, os estudos brasileiros ainda precisam ser ampliados, visando a melhor elaboração dos indicadores, o que aponta para a urgência de revisão da nova versão do DIT-2. O MJT, por sua vez, mensura a competência do juízo moral. É um experimento objetivo que se propõe verificar a coerência na estrutura de juízo. Isso faz com que difira dos demais instrumentos em uso, nas pesquisas sobre desenvolvimento moral. No Brasil, tem-se usado a versão estendida do MJT, visto que há diferença consistente e significativa nos resultados do dilema da eutanásia, quando cotejados ao dilema do operário e do juiz.

Esses instrumentos têm sido empregados de modo crescente, em pesquisas sobre moralidade, por meio dos quais o julgamento e/ou a competência moral são avaliados em diferentes contextos - escolas, universidades, ambiente de trabalho, sistemas prisionais ou socioeducativos etc. - e relacionados com uma diversidade de fatores, tais como: formação acadêmica e profissional, características da personalidade, gênero, orientação social, tomada de perspectiva e capacidade empática, maturidade e autoconceito, delinquência, programas de Educação Moral e em Valores, religiosidade, uso de álcool, dentre outros.

\section{Referências Bibliográficas}

Bataglia, P. U. R. (1996). Um estudo sobre o juízo moral e a questão ética na prática da Psicologia. Dissertação de mestrado, Universidade de São Paulo, São Paulo.

Bataglia, P. U. R. (2001). A Construção da competência moral e a formação do psicólogo. Tese de doutorado, Universidade de São Paulo, São Paulo.

Bataglia, P. U. R., Schillinger-Agati, M., \& Lind, G. (2006). Moral segmentation in MJT studies: cultural influences [Resumo]. $32^{\text {nd }}$ Annual Conference of the Association of Moral Education - Getting Involved: global citizenship development and sources of moral values. Proceedings (p. 54-55). Friburgo: Suíça.

Biaggio, A. M. B. (1984). Pesquisas em psicologia do desenvolvimento e da personalidade. Porto Alegre, RS: Editora da UFRGS.

Biaggio, A. M. B. (1992). Julgamento moral, ansiedade e diferenças de sexo. Psico, 24(2), 7-27.

Biaggio, A. M. B. (2002). Lawrence Kohlberg: ética e educação moral. São Paulo: Moderna.

Biaggio, A. M. B., \& Barreto, M. (1989). Adaptação brasileira do Sociomoral Reflection Objetive Measure (SROM). [S.L.: s.n.].

Biaggio, A. M. B., Shimizu, A. M., \& Martinez, T. M. (2001). DIT-2 Opiniões sobre Problemas Sociais - Tradução e Adaptação do Defining Issues Test - 2. Center for the Study of Ethical Development, Universidade de Minnesota, Minneapolis, Estados Unidos.

Bzuneck, J. A. (1979). Julgamento moral de adolescentes delinquentes e não delinquentes em relação com a ausência paterna. Tese de doutorado, Universidade de São Paulo, São Paulo.

Camino, C. S., Batista, L., Reis, R., Rique, J. N., Luna, V., \& Cavalcanti, M. G. (1994). A transmissão verbal de valores morais em personagens de TV. Psicologia Reflexão e Crítica, 7(1), 29-49.

Camino, C., Luna, V., Alves, A., Silva, M., \& Rique, J. (1988). Primeiros resultados da reformulação e adaptação do Definig Issues Test. [Resumo]. In Sociedade Brasileira de Psicologia (Org.), XVIII Reunião Anual de Psicologia. Anais (p.236). Ribeirão Preto: Autor.

Camino, C., Luna, V., Alves, A., Silva, M., \& Rique, J. (1989). Reformulação e adaptação do Defining Issues Test. [Resumo]. In XXII Congresso Interamericano de Psicologia. Anais (p.72). Buenos Aires: Autor.

Camino, C., Moraes, R., \& Galvão, L. (2006). Diferenças de gênero no raciocínio moral. In Simpósio Nacional de Psicologia Social e do Desenvolvimento e X Encontro Nacional Procad - Psicologia Capes. Violência e Desenvolvimento Humano. Textos completos. (pp. 101-109). Vitória, Espirto Santo.

Campbell, R. L., \& Christopher, J. C. (1996). Moral development theory: a critique of this Kantian pressupositions. Development Review, 16(1), 1-47.

Colby, A., \& Kohlberg, L. (1987). The measurement of moral judgment. Nova York: Cambridge University Press.

Díaz-Aguado, M. J., \& Medrano, C. (1999). Construção moral e educação: uma aproximação construtivista para trabalhar os conteúdos transversais. Bauru: Edusc.

Flanagan, O. (1996) Psychologie morale et éthique. Paris: Press Universitaires 
de France.

Gibbs, J. C., Arnold, K. D. E., \& Burkhart, J. E. (1984). Sex differences in the expression of moral judgement. Child Development, 55, 1040-1043.

Gilligan, C. (1993). Uma voz diferente: psicologia da diferença entre homens e mulheres da infância à idade adulta. Rio de Janeiro: Rosa dos Ventos.

Glanzer, D., Nipe, G., \& Lind, G. (2007). Does Cross-Cultural Experience Foster Moral Judgment Competence in College Students?Poster apresentado na 31st Meeting of the Association for Moral Education. Cambridge: Massachussets.

Habermas, J. (1983). Consciência moral e agir comunicativo. Rio de Janeiro: Tempo Brasileiro.

Hare, R. M. (1982). Ethical theory and utilitarism. In A. Sen \& B. Williams (Orgs.), Utilitarism and beyond (pp.23-38). Cambridge: Cambridge University Press.

Hebert, P., Meslin, E., Dunn, E. V., Buirn N., \& Reid, R. (1990). Evaluating ethical sensitivity in medical students: using vignettes as an instrument. Journal of Medical Ethics, 16, 141-145.

Kohlberg, L. (1992). Psicología del desarrollo moral. Bilbao Spain: Desclée de Brouwer.

Koller, S. H., Biaggio, A. M. B., Lopes, S., Rique, J. N., Camino, C., Dias, M. G., \& Costa, A. E. (1994). Uma investigação sobre os instrumentos de medida de maturidade de julgamento moral em uso no Brasil. Psicologia Reflexão e Critica, 7(1), 5-14.

Koller, S. H., Biaggio, A. M. B., \& Viñas, A. (1992). Efeitos do sexo do protagonista na avaliação de diferenças de gênero no julgamento moral. Psicologia: Teoria e Pesquisa, 8, 327-339.

La Taille, Y. (1998). Limites: três dimensões educacionais. São Paulo: Ática.

Lepre, R. M. (2005). Raciocínio Moral e uso abusivo de álcool por adolescentes. Tese de doutorado, Universidade Estadual Paulista, Marília, São Paulo.

Lepre, R. M., \& Martins, R. A. (2009). Raciocínio Moral e uso abusivo de bebidas alcoólicas por adolescentes. Paidéia, 42, 39-46.

Lind, G. (1999). An introduction to the moral judgment test, MJT. Disponível em http://www.unikonstanz.de/ag-moral/mut/mjt-intro.htm.

Lins, M. T. D. F. (1993). Desenvolvimento moral em universitários: uma intervenção educacional. Dissertação de mestrado, Universidade Federal da Paraíba, João Pessoa.

Lourenço, O. M. (2002). Psicologia de desenvolvimento moral: teoria, dados e implicações. Coimbra: Almeida.

Mattos, G. G., Shimizu, A. M., \& Bervique, J. A. (2008). A sensibilidade ética e o julgamento moral de estudantes de Psicologia. Arquivos Brasileiros de Psicologia, 60 (3), 113-128.

Menin, M. S. S. (1996). Desenvolvimento Moral: refletindo com pais e professores. In L. Macedo (Org.), Cinco estudos sobre Educação Moral (pp. 37-104). São Paulo: Casa do Psicólogo.

Moreno, C. (2005). Moral education in higher education and the transformation of a concern: a historical account. Paper apresentado na 31st Annual Meeting or the Association for Moral Education. Cambridge: Massachussets.
Oliveira, M. S. (2008). Desenvolvimento da Competência de juizo moral e ambiente de ensino-aprendizagem: uma investigação com estudantes de graduação em enfermagem. Dissertação de mestrado, Escola Nacional de Saúde Pública, Fundação Oswaldo Cruz, Rio de Janeiro.

Pérez Delgado, E., \& Mestre Escrivá, V. (1995). El crecimiento moral: programas psicoeducativos y su eficacia en el aula. Barcelona: Universitat de Valência.

Pérez Delgado, E., Serra-Desfilis, R., \& Carbonell-Vaya, E. (1986). Jalones históricos en la Psicología del desarrollo de lo moral. Revista de la Historia de la Psicología, 7(2), 69-89.

Piaget, J. (1954). Les relations entre l'intelligence et l'affectivité dans le développement de l'enfant. Bulletin de Psychologie, 8, 1-195.

Piaget, J. (1994). O juízo moral na criança. São Paulo: Summus. (Publicado originalmente em 1932)

Piaget, J. (1997). Seis estudos de psicologia. Rio de Janeiro: Forense Universitária. (Publicado originalmente em 1964)

Rest, J. (1986). DIT Manual: manual for the Defining Issues Test. Minneapolis: University of Minnesota.

Rest, J., \& Narvaez, D. (1998). Guide for DIT-2. Minneapolis: Center for the Study of Ethical Development, University of Minnesota.

Rest, J., Narvaez, D., Bebeau, M. J., \& Thoma, S. J. (1999). Postconventional moral thinking: a neo-kohlbergian approach. Mahwah: Lawrence Erlbaum Associates.

Sambuy, M. T. C., Barros, N. P., Nogueira, R. M., Marcolino, J. A. M., \& Mathias, L. A. S. T. (2005). Medida da sensibilidade ética: estudo em estudantes de Medicina na cidade de São Paulo. Relatório da pesquisa realizada junto ao Programa Institucional de Bolsas de Iniciação Científica/Conselho Nacional de Pesquisa - PIBIC-CNPq. Faculdade de Ciências Médicas da Santa Casa de São Paulo.

Schillinger, M. (2006). Learning environments and moral development: how university education fosters moral judgment competence in Brazil and two German-speaking countries. Aachen: Shaker-Verlag.

Shimizu, A. M. (2002). Representações sociais e julgamentos morais de jovens: um estudo intercultural comparando duas abordagens teóricometodológicas. Tese de doutorado, Universidade Estadual Paulista, Marília, São Paulo.

Shimizu, A. M. (2004). Defining Issues Test: fidedignidade da versão brasileira e ponderações acerca de seu uso em pesquisas sobre moralidade. Psicologia Reflexão e Crítica, 17(1), 5-14.

Shimizu, A. M., \& Urano, M. M. (2004). Defining Issues Testes 1 y 2: cálculo de confiabilidad de las versiones castellanas y consideraciones cerca de su uso en estudios sobre moralidad. Investigaciones en Psicología Revista del Instituto de Investigaciones, 9(2), 41-57.

Slovácková, B. (2001). Moral Competence and Moral Attitudes of Students at the Medical Faculty of Charles University in Hradec Králové. Univerzity Karlovy v Hradci Králové. Psychiatrie, 5(2), 74-79.

Patricia Unger Raphael Bataglia, doutora em Psicologia Social pela Universidade de São Paulo, é professora Assistente Doutora da Universidade Estadual Paulista, Marília. Endereço para correspondência: Rua Turiaçu, 152 - ap. 21, Perdizes, São Paulo - SP. CEP 05005-000. Fones: (11) 3663-1162/(11) 9669-7168 e-mail: patriciabat@terra.com.br Alessandra de Morais, doutora em Educação pela Universidade Estadual Paulista, é professora Assistente Doutora da Universidade Estadual Paulista, Marília. E-mail: ashimizu@flash.tv.br Rita Melissa Lepre, doutora em Educação pela Universidade Estadual Paulista, é professora Assistente Doutora da Universidade Estadual Paulista, Bauru. E-mail: melissa@fc.unesp.br 